\title{
Comparison of Efficacy and Safety of Theophylline, Doxophylline and Acebrophylline as an Add-On in the Management of Chronic Obstructive Pulmonary Disease
}

\author{
Ranjit Gain ${ }^{1}$, Rupam Kumar T. A. ${ }^{2}$, Pronoy Sen ${ }^{3}$, Vignesh A. ${ }^{4}$ \\ ${ }^{1}$ Department of Biochemistry, Burdwan Medical College and Hospital, Bardhaman, West Bengal, India. ${ }^{2}$ Department of \\ Chest Medicine, Burdwan Medical College and Hospital, Bardhaman, West Bengal, India. ${ }^{3}$ Department of Chest \\ Medicine, Burdwan Medical College and Hospital, Bardhaman, West Bengal, India. ${ }^{4}$ Department of Pulmonary \\ Medicine, Burdwan Medical College and Hospital, Bardhaman, West Bengal, India.
}

\section{ABSTRACT}

\section{BACKGROUND}

COPD is defined by GOLD as a disease characterized by airflow limitation that is not fully reversible. The chronic airflow limitation characteristic of COPD is caused by small airway disease (obstructive bronchiolitis) and parenchymal destruction (emphysema). We wanted to compare the efficacy and safety of theophylline, doxophylline and acebrophylline in the management of stable COPD patients.

\section{METHODS}

A prospective observational study was conducted in Burdwan Medical College and Hospital where 125 newly diagnosed adult stable COPD patients were divided into three groups each of which received theophylline, doxophylline or acebrophylline as add-on therapy over the standard for COPD. The study was conducted over a period of 13 months for spirometric parameters, severity of dyspnoea, quality of life. Assessment of adverse drug reactions was done by Naranjo's causality assessment scale.

\section{RESULTS}

Patients of all three groups showed statistically significant difference in improvement in spirometric parameters and modified medical research council score and quality of life within each group. Few adverse effects like nausea were found in 2 (5.88\%) patients of theophylline group, $2(6.06 \%)$ patients of doxophylline group, and 2 $(6.06 \%)$ patients of acebrophylline group. Palpitation was found in $1(2.94 \%)$ patient of theophylline group while headache was found in $2(6.06 \%)$ patients of acebrophylline group. Thus, it is seen that cardiological complications are more in theophylline group.

\section{CONCLUSIONS}

In this study, all patients had shown some form of improvement in spirometry parameters after treatment which was maximum with doxophylline. Adverse effects were similar and non-serious in all the study patients.

\section{KEY WORDS}

Theophylline, Doxophylline, Acebrophylline, COPD Management
Corresponding Author: Dr. Rupam Kumar T. A., \#120, Vivekananda Road, Chotonilpur, PO-Sripally, Dist-Purba, Bardhaman-713103, West Bengal, India.

E-mail: rupamkumarta@yahoo.com

DOI: $10.14260 / \mathrm{jemds} / 2020 / 45$

Financial or Other Competing Interests: None.

How to Cite This Article: Gain R, Kumar RTA, Sen P, et al. Comparison of efficacy and safety of theophylline, doxophylline and acebrophylline as an addon in the management of chronic obstructive pulmonary disease. J. Evolution Med. Dent. Sci. 2020;9(04):191-194, DOI: 10.14260/jemds/2020/45

Submission 26-11-2019,

Peer Review 05-01-2020,

Acceptance 11-01-2020,

Published 27-01-2020. 


\section{BACKGROUND}

Chronic obstructive pulmonary disease (COPD) has been defined by The Global Initiative for Obstructive Lung Disease (GOLD) as a disease state characterised by airflow limitation that is not fully reversible. The chronic airflow limitation characteristic of COPD is caused by a mixture of small airway disease (obstructive bronchiolitis) and parenchymal destruction (emphysema), the relative contributions of which vary from person to person.(1) COPD is a leading cause of morbidity and mortality worldwide and a major health problem. It was found that worldwide, COPD affects more than 400 million people.(2) According to WHO, approximately $5 \%$ of all deaths globally were from COPD in 2005, which figured more than 3 million deaths from COPD in 2005. It is a social and economic burden in our country regarding cost of treatment. WHO has also put a caution that total deaths from COPD is projected to increase by more than $30 \%$ in the next 10 years unless urgent action is taken to reduce risk factors. It was also estimated that COPD will become the third leading cause of death worldwide in 2030.-

Methyl xanthines has been used in COPD since long Theophylline is a methyl xanthine derivative which is a popular agent since long in the management of COPD. However, short $1 / 2$, frequent administration and toxicity profile were some factors which raised concern about compliance and patient safety.(3,4) theophylline sustained released was a significant development to improve patient compliance by reducing frequency of dosing and inter dose plasma level fluctuations. ${ }^{(5,6)}$ Later doxophylline emerged as a newer alternative the theophylline which has a longer $\mathrm{t}_{1 / 2}$. Therefore, frequency of administration was reduced, and patient compliance is likely to be improved.(7-9) acebrophylline is a combination of ambroxol + theophylline 7 -acetate and is required only twice daily. It is claimed to be superior due to inclusion of ambroxol in the compound and claimed to be better tolerated.(10-12) Hence the study was conducted to compare of efficacy and safety between theophylline, doxophylline and acebrophylline in the management of stable COPD patients.

We wanted to assess and compare the efficacy and safety of theophylline, doxophylline and acebrophylline in applied dose.

\section{METHODS}

This is an open label, prospective, observational study conducted in the Department of Pharmacology and the Department of Chest Medicine, Burdwan Medical College and Hospitals, Burdwan over a period of 21 months among all consenting adults patients with newly diagnosed COPD with FEV1/FVC $<0.7$ (post bronchodilators), FEV1 $\geq 30 \%$ to $<80 \%$ and going to get theophylline, doxophylline and acebrophylline as add on therapy over the standard therapy for their disease.

\section{Inclusion Criteria}

1. Diagnosed stable COPD patient

2. Age: 40 yrs. and above, both genders.
3. Post bronchodilator FEV1/FVC is $<0.7$

4. FEV1 $<80 \%-\geq 30 \%$ of predicted (GOLD severity criteria II \& III)

5. Receives theophylline, doxophylline or acebrophylline as add-on therapy over the standard therapy for COPD.

\section{Exclusion Criteria}

1. Bronchial asthma.

2. Any major cardio vascular disease.

3. Co-administration of any drugs which may inhibit metabolism of theophylline or similar drugs.

4. Patient with Asthma COPD Overlap Syndrome (ACOS).

5. Bronchiectasis.

6. Bronchiolitis.

7. Tuberculosis.

8. Chronic heart failure.

\section{Study Variables}

1. Spirometric parameter-FEV1\%.

2. Severity of dyspnoea by mMRC dyspnoea scale.

3. Quality of life by CAT score.

\section{Sample Size}

1. Total no. of patients $=100$.

2. Average no of patients attending chest OPD per year $=250$.

3. Newly diagnosed cases $=125$ ( $50 \%$ of total no.)

4. $20 \%$ loss in follow up.

5. Samples were enrolled till mid-January 2018.

6. Follow up till February 2018.

Consecutive samples were taken till the desired size was reached

Study was conducted after obtaining approval from Institutional Ethics Committee (IEC), of Burdwan Medical College, Burdwan. Written informed consent was obtained from each patient in the consent form in English or in vernacular language. It was a prospective and observational study. All suspected symptomatic COPD patients who presented with the symptoms of chronic cough with excessive sputum formation, associated with shortness of breath and any other relevant symptoms was evaluated for pulmonary function test by spirometry at the beginning of the study for presence of COPD. The patients who were receiving tiotropium bromide and or fluticasone propionate as per their disease stage (following GOLD guidelines) and add on theophylline, doxophylline or acebrophylline were enrolled over a period of one year.

Eligible patients were divided in to three groups, Group A: Patient prescribed to take theophylline oral tablets $(100 \mathrm{mg}$ ) thrice daily, Group B: patient prescribe to take doxophylline (400 mg) oral tablets twice daily and Group C: patient prescribed to take acebrophylline $(100 \mathrm{mg})$ capsules twice daily. All the study patients were followed up after one week and six weeks. FEV1\% of the patients were recorded in case record form. Severity of dyspnoea was assessed by modified Medical Research Council (mMRC) scale and quality of life was evaluated by CAT score questionnaire, from the beginning to end of the study. All the patients received uniform medications. All of the patients received inhalational Long Acting Muscarinic Agonist (LAMA) and SOS Short acting Bronchodilator. The presence or absence of any adverse 
reactions were detected during study period that is assessed by on the basis of the patients' interviews. The sign and symptoms of drug reactions were also observed. Causality assessment of adverse drug reactions was done by Naranjo's causality assessment scale to establish the adverse drug reaction.

\section{Parameters for Assessment}

1. FEV1\% (post bronchodilator) -- by spirometry.

2. Clinical improvement by shortness of breath -- by mMRC scale.

3. Quality of life assessed by CAT score.

4. Adverse drug reactions monitoring and causality assessment.

\section{Statistical Analysis}

All data was analysed by standard statistical methods. Data analysis was done by using statistical package for social science (SPSS). One way ANOVA test was applied wherever applicable to find out statistical differences and $p$ value $<0.05$ were considered statistically significant.

\section{RESULTS}

Total 250 patient of COPD attending out-patient department of chest medicine, Burdwan Medical College and Hospital Burdwan, among them 125 patients who were newly diagnosed, were recruited in this study. Out of this 100 patients were analysed and 25 were lost to follow up. This included 34 patients in theophylline group, 33 patients in doxophylline group and 33 patients in acebrophylline group. In group A 22 (64.7\%) patients belonged to GOLD grade 2 and $12(35.3 \%)$ patients belonged to GOLD grade 3 . In group B 24 $(72.72 \%)$ patients belonged to GOLD grade 2 and 9 (27.28) patients belonged to GOLD grade 3. In group C $20(60.06 \%)$ patients belonged to GOLD grade 2 and 13 (39.94\%) patients belonged to GOLD grade 3. No significant ECG changes were detected.

\begin{tabular}{|c|c|c|c|c|c|}
\hline \multirow{2}{*}{\multicolumn{2}{|c|}{ Groups }} & \multicolumn{3}{|c|}{ Treatment Category } & \multirow{3}{*}{\begin{tabular}{|c|}
$\mathbf{p}^{*}$ \\
0.224
\end{tabular}} \\
\hline & & Theophylline & Doxophylline & Acebrophylline & \\
\hline \multirow{2}{*}{ Gender } & Male & 27 & 31 & 28 & \\
\hline & Female & 7 & 2 & 5 & 0.224 \\
\hline Age (Yrs.) & Mean & 59.35 & 55.96 & 62.27 & 0.029 \\
\hline \multirow{2}{*}{ Religion } & Hindu & 21 & 24 & 21 & 0.324 \\
\hline & Muslim & 12 & 9 & 12 & 0.324 \\
\hline Packets/Day & Mean & 0.8939 & 1.0758 & 1.0303 & 0.339 \\
\hline Pack-year & Mean & 24.8824 & 26.8485 & 25.8485 & 0.828 \\
\hline \multicolumn{6}{|c|}{$\begin{array}{l}\text { Table 1. Distribution of Study Subjects According to } \\
\text { Demographic Variables }(n=100)\end{array}$} \\
\hline \multicolumn{6}{|c|}{$\begin{array}{l}{ }^{*} \text { Majority of the patients were Male, Hindu, Mean Age Group is } 59.35 \text { years in } \\
\text { theophylline group, } 55.96 \text { years in doxophylline group and } 62.27 \text { years in } \\
\text { acebrophylline group, Mean Packets per Day is around } 1 \text { for the three groups and } \\
\text { Number of Pack Years is around } 25 \text { for each group. }\end{array}$} \\
\hline
\end{tabular}

\begin{tabular}{|c|c|c|c|c|}
\hline $\begin{array}{c}\text { Treatment } \\
\text { Category }\end{array}$ & Theophylline & Doxophylline & Acebrophylline & $\mathbf{p}^{*}$ \\
\hline FEV1 at Day 0 & $55.29 \pm 9.77$ & $50.61 \pm 10.96$ & $59.42 \pm 9.64$ & 0.003 \\
\hline FEV1 at Day 7 & $56.85 \pm 10.52$ & $51.24 \pm 10.76$ & $60.27 \pm 9.89$ & 0.003 \\
\hline FEV1 at Day 42 & $61.15 \pm 10.86$ & $55.06 \pm 11.21$ & $64.64 \pm 10.02$ & 0.002 \\
\hline \multicolumn{5}{|c|}{ Table 2. Effect on Pulmonary Function (Change in FEV1) $(n=100)$} \\
\hline \multicolumn{5}{|c|}{${ }^{*}$ p-value less than 0.05 is significant (one way ANOVA) } \\
\hline
\end{tabular}

\begin{tabular}{|c|c|c|c|c|}
\hline $\begin{array}{c}\text { Treatment } \\
\text { Category }\end{array}$ & Theophylline & Doxophylline & Acebrophylline & $\mathbf{p}^{*}$ \\
\hline mMRC at Day 0 & $2.76 \pm 0.85$ & $2.91 \pm 0.58$ & $2.91 \pm 0.52$ & 0.596 \\
\hline mMRC at Day 7 & $2.50 \pm 0.71$ & $2.55 \pm 0.62$ & $2.42 \pm 0.50$ & 0.722 \\
\hline mMRC at Day 42 & $2.00 \pm 0.74$ & $2.15 \pm 0.62$ & $2.15 \pm 0.44$ & 0.507 \\
\hline \multicolumn{6}{|l|}{ Table 3. Change of mMC Scale with Treatment (n=100) } \\
\hline *p-value less than 0.05 is significant. (one way ANOVA) \\
\hline
\end{tabular}

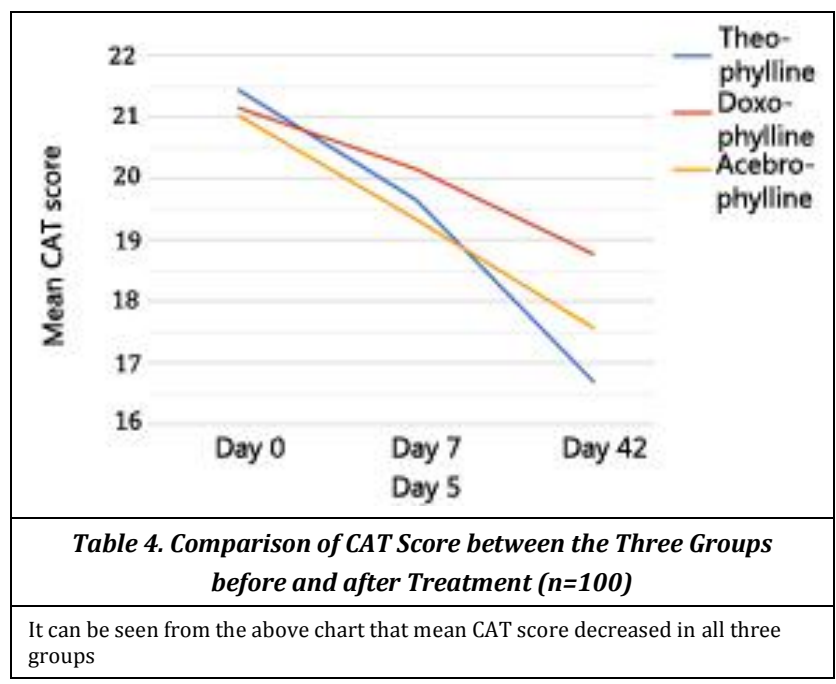

\begin{tabular}{|c|c|c|c|}
\hline \multirow{2}{*}{$\begin{array}{l}\text { Adverse Drug } \\
\text { Reaction }\end{array}$} & \multicolumn{3}{|c|}{ Drug Category } \\
\hline & $\begin{array}{c}\text { Theophylline } \\
n=34\end{array}$ & $\begin{array}{c}\text { Doxophylline } \\
n=33\end{array}$ & $\begin{array}{c}\text { Acebrophylline } \\
n=33\end{array}$ \\
\hline Nausea & $2(5.88 \%)$ & $2(6.06 \%)$ & $2(6.06 \%)$ \\
\hline Pain Abdomen & $1(2.94 \%)$ & $1(3.03 \%)$ & $1(3.03 \%)$ \\
\hline Headache & 0 & 0 & $2(6.06 \%)$ \\
\hline Sleep Disturbances & 0 & 0 & 0 \\
\hline Irritability & 0 & 0 & 0 \\
\hline Restlessness & 0 & 0 & 0 \\
\hline Palpitation & $1(2.94 \%)$ & 0 & 0 \\
\hline Tremor & 0 & 0 & 0 \\
\hline \multicolumn{4}{|c|}{$\begin{array}{c}\text { Table 5. Occurrence of Various Adverse Events among } \\
\text { the Three Groups of Study Patients (n=100) }\end{array}$} \\
\hline $\begin{array}{l}\text { is seen from table } 5 \\
\text { cebrophylline group }\end{array}$ & number of adve & erse events was hig & er in the patie \\
\hline
\end{tabular}

\section{DISCUSSION}

In the present study mean age of the study population was more than 50 years of age, which was consistent with the previous literatures as the disease had highest prevalence in fifth and sixth decades of life. After analysis of data in this study it showed COPD is more common in male in our country, majority of the patients in our study were male and belonged to Hindu community. Moreover, smoking is the most common aetiology of COPD and smoking habits were more pronounced in male over females in our country due to some social factors. At baseline spirometric variables (FEV1) were similar and statistically significant in three treatment groups. After treatment there was improvement in the spirometric variables and that is statistically significant within same group and were sustained throughout the treatment period up to 42 days.

In the present study, theophylline showed a statistically significant improvement in FEV1\% within the group at day 7 and day 42 ( $p$ value $<0.05$ ). In mMRC scale score from baseline statistically significant improvement is found within the group of each drug. It indicated improvement of quality of life. In respect of CAT score statistically significant change was found in all three groups after treatment; indicating quality of life had improved. But the changes between the groups were not 
statistically significant. In the present study acebrophylline has distinct advantages on pulmonary function in the patients suffering from COPD.

Adverse drug reaction in all three groups were mild in severity. Gastrointestinal side effects were nausea, pain abdomen and cardiovascular side effect was palpitation found in theophylline group. Cardiovascular side effects were not found in doxophylline and acebrophylline groups. Gastrointestinal side effects are common in all three groups. Reduced chances of cardiovascular side effects with acebrophylline was possibly due to the fact that ambroxol present in it attains higher concentration in blood than its xanthine derivatives which are associated with cardiovascular side effect. Another side effect headache is found in acebrophylline group, but it is very rare, in comparison with doxophylline and theophylline groups. In comparison with safety all three group of drugs have same safety profiles.

\section{Limitations}

1. This study was an observational study conducted over a short period.

2. Small sample size.

3. Sampling method - convenience sampling prone to bias.

4. Short follow-up.

\section{CONCLUSIONS}

The present study has detected improvement in COPD symptoms with theophylline, doxophylline and acebrophylline. There was also improvement in quality of life in all the treated patients. Though change in pulmonary function parameter was superior with doxophylline, all the three compounds resulted a similar change in quality of life parameters. All the three drugs were well tolerated in the studied doses. However, future prospective study is recommended with the large sample size to support these findings.

\section{REFERENCES}

[1] Global strategy for diagnosis, management and prevention of COPD - 2016. Global initiative for chronic obstructive lung disease - GOLD. [cited 2016 Nov 11]. http://goldcopd.org/global-strategy-diagnosismanagement-prevention-copd-2016/
[2] Gupta D, Agarwal R, Aggarwal AN, et al. Guidelines for diagnosis and management of chronic obstructive pulmonary disease: Joint ICS/NCCP (I) recommendations. Lung India Off Organ Indian Chest Soc 2013;30(3):22867. http://www.who.int/respiratory/copd/burden/en/

[3] Molfino NA, Zhang P. A meta-analysis on the efficacy of oral theophylline in patients with stable COPD. Int J Chron Obstruct Pulmon Dis 2006;1(3):261-6.

[4] Gaudreault P, Guay J Theophylline poisoning. Pharmacological considerations and clinical management. Med Toxicol 1986;1(3):169-91.

[5] Barnes PJ Theophylline: new perspectives for an old drug. Am J Respir Crit Care Med 2003;167(6):813-8.

[6] Barnes PJ Theophylline in chronic obstructive pulmonary disease: new horizons. Proc Am Thorac Soc 2005;2(4):334-9, discussion 340-1.

[7] Dini FL, Cogo R. Doxophylline: a new generation xanthine bronchodilator devoid of major cardiovascular adverse effects. Curr Med Res Opin 2001;16 (4):258-68.

[8] Sacco C, Braghiroli A, Grossi E, et al. The effects of doxophylline versus theophylline on sleep architecture in COPD patients. Monaldi Arch Chest Dis 1995;50 (2):98103.

[9] Shukla D, Chakraborty S, Singh S, et al. Doxophylline: a promising methylxanthine derivative for the treatment of asthma and chronic obstructive pulmonary disease. Expert Opin Pharmacother 2009;10(14):2343-56.

[10] Tapadar SR, Das M, Chaudhuri AD, et al. The effect of acebrophylline vs sustained release theophylline in patients of copd- a comparative study. J Clin Diagn Res 2014;8 (9):MC11-MC4.

[11] Pozzi E. Acebrophylline: an airway mucoregulator and anti-inflammatory agent. Monaldi Arch Chest Dis 2007;67(2):106-15.

[12] Agliati G. Effects of a short course of treatment with acebrophylline on the mucus rheological characteristics and respiratory function parameters in patients suffering from chronic obstructive pulmonary disease. J Int Med Res 1996;24(3):302-10 